\title{
What are patient-reported outcomes and why they are important: improving studies of preschool wheeze
}

\author{
Heidi Makrinioti (D) , ${ }^{1}$ Andrew Bush (D) , ${ }^{2,3}$ Chris Griffiths ${ }^{4}$
}

\begin{abstract}
${ }^{1}$ Department of Paediatrics, Imperial College Healthcare NHS Trust, London, UK ${ }^{2}$ Department of Paediatric Respiratory Medicine, Royal Brompton Hospital, London, UK ${ }^{3}$ Division of Medicine, Imperial College, London, United Kingdom

${ }^{4}$ Centre for Paediatrics, Blizard Institute, Barts and the London School of Medicine and Dentistry, Queen Mary University of London, London, UK
\end{abstract}

\section{Correspondence to}

Dr Heidi Makrinioti, Paediatrics, Imperial College Healthcare NHS Trust, London W12 OHS, UK; heidimakrinioti@gmail.com

Received 21 February 2019 Revised 16 August 2019 Accepted 23 August 2019 Published Online First 31 August 2019

\section{(D) Check for updates}

(C) Author(s) (or their employer(s)) 2020. No commercial re-use. See rights and permissions. Published by BMJ.

To cite: Makrinioti $\mathrm{H}_{\text {, }}$ Bush A, Griffiths C. Arch Dis Child Educ Pract Ed 2020;105:185-188.

\begin{abstract}
There are no outcomes-based commissioning structures in child health. This needs to change. Preschool wheeze is a very common condition. Many families present at emergency departments with their wheezy children and stay briefly. This highlights that this group of children may be lacking a more personalised approach. There are no user-friendly patient-reported outcome measures in preschool wheeze. This needs to change. Research in this area is therefore highly anticipated.
\end{abstract}

\section{INTRODUCTION}

The involvement of patients in both the design and the conduct of research has been increasingly promoted by research bodies and policymakers. All members of the public can offer their expertise as users of the healthcare system but especially patients who are living with a longterm medical condition. Patients are now involved in both the design of healthcare interventions and relevant research but also in giving feedback on healthcare services provision and in reviewing research proposals and interviewing healthcare research staff. ${ }^{1}$ It is also important to note that many journals will now routinely reject submitted studies where patients have not been involved from the very beginning in the design of the study.

The success of research design and implementation can only be assessed by measurable outcomes. Traditionally, outcomes of research interventions are defined by the research team. In paediatric respiratory conditions, outcomes related to number of hospital attendances, use of acute medication and lung function measurement have been used to monitor response to interventions including pharmacological treatment, but this is changing. Understanding what matters to patients has started being considered as equally important conventional outcome(s). By understanding which the important outcomes are for our patients, we will be in a better position to design meaningful interventions including behaviour modifications that are responsible for increasing numbers of avoidable emergency department admissions and poor treatment compliance in the UK.

\section{WHAT IS A PATIENT-REPORTED OUTCOME MEASURE?}

These are tools measuring outcomes that matter to patients, more specifically reflecting patients' or caregivers' perspective on the impact of the condition on their lives and how illness is experienced (eg, 'can I now climb my stairs?', rather than 'has my spirometry improved?'). These tools aim to capture the patient's perspective, so patient involvement is required in the development of patientreported outcome measure (PROMs). When it comes to the subjective experience of their condition, patients and/or their carers can be considered as 'experts' and they can bring value in conversations/ consultations and in defining the importance of commonly used outcomes, such as length of hospital stay. As opposed to Quality of Life Questionnaires, PROMs are brief tools designed to assess level of health and/or disability as perceived by patients/caregivers apart from healthrelated quality of life only. In 2009, it was suggested that value in healthcare should be assessed by reintroducing point of care use of PROMs. ${ }^{2}$ These are now being used to track outcomes of surgical operations and in the USA, PROMs and clinical data are driving improvements in results for 


\section{Box 1 Examples of PROMs and their use}

PROM as a clinical monitoring tool

PREOM-BMP, ${ }^{20}$ an 11 -item questionnaire measuring the impact of bowel management in children and families' quality of life. (PREOM-BMP, patient-reported experience and outcome measure in a bowel management programme.)

PROM used as an outcome measurement tool in research.

Pedi-IKDC ${ }^{21}$ a 15-item instrument assessing health-related quality of life in children with knee ligament injury. (PediIKDC, Pedi International Knee Documentation Committee.)

PROM used as a quality of care indicator.

EQ-5D $\underline{3}$ a five-item questionnaire that assesses mobility, self-care, pain, usual activities and psychological status and has been used in the NHS as an outcome measure for patients undergoing hip replacement operation. (EQ-5D, Euro-Quality of Life.)

PROM, patient-reported outcome measure.

children with inflammatory bowel disease. ${ }^{34}$ In the National Health Service (NHS), PROMs have been successfully used to inform quality of care for patients undergoing hip replacement surgery, by highlighting the variation in cost between different hospitals and by suggesting new measures of assessment of efficacy

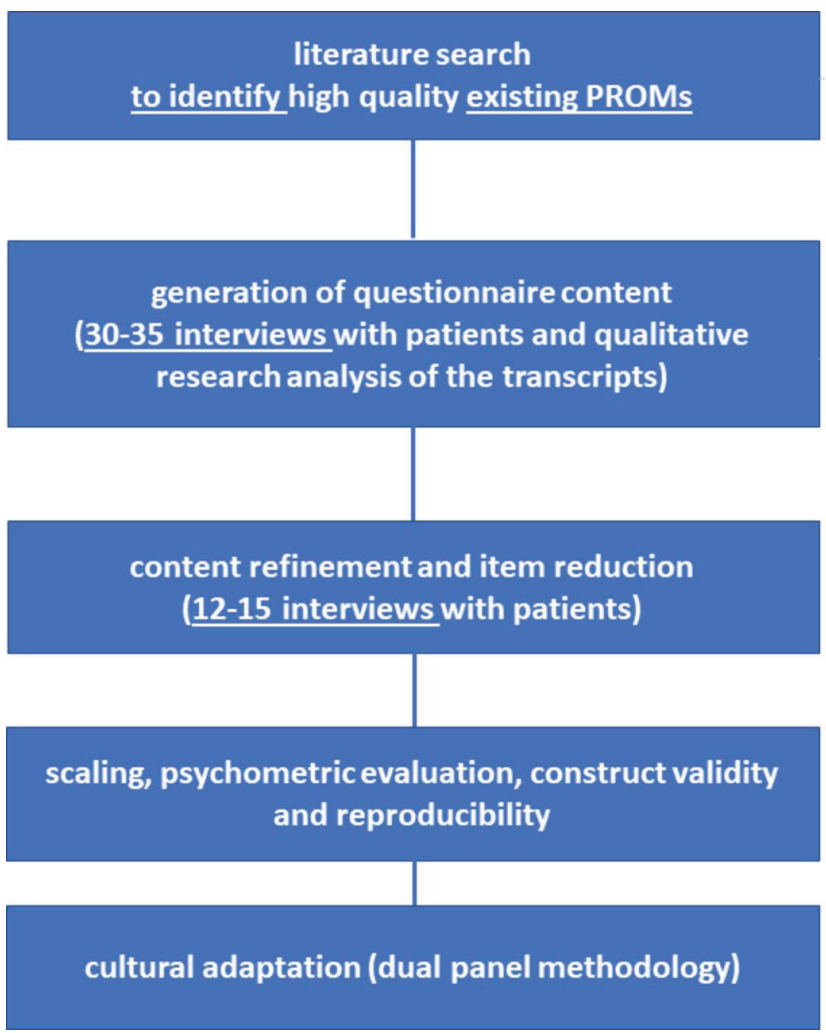

which are of real importance to the patient. ${ }^{5}$ Physicians are often reluctant to use PROMs routinely because of the time they take to use, and a lack of confidence in their value. By contrast, many patients welcome PROMs and believe that they need to be used routinely in their management. ${ }^{6}$ There are examples of validated PROMs in box 1.

\section{HOW IS A PROM DEVELOPED?}

The first step is the definition of the conceptual and measurement model. The conceptual model provides a structured representation of the items (constructs) that will be included in the PROM. This conceptual model is usually based on literature review and provides the framework of reference. The subsequent measurement model is the result of qualitative research with patients and families and aims to map the individual items in the PROM to the construct. ${ }^{7}$ This is an important stage when some of the constructs will not be mapped to items if patients/carers do not consider these as important to be included in the PROM tool. The steps of the design of a PROM tool are shown in figure 1.

\section{WHY DO WE NEED PROMS FOR PRESCHOOL WHEEZE?}

Recurrent wheeze in preschool children is common. In the UK, the highest number of hospital admissions with wheeze was in children less than 5 years old. ${ }^{89}$ The majority of preschool children with wheeze suffer from recurrent commonly viral induced attacks,

Figure 1 Figure describing the development, validation and adaptation of PROMs. PROMs, patient-reported outcome measure. 
and although most remit over time, ${ }^{10}$ the associated morbidity and hospitalisations throw a heavy burden on both the healthcare systems and the families. However, there is often a mismatch between wheeze severity and parental response, in particular whether hospital management is sought. Several studies show that nearly a third of children who present to emergency departments with a wheeze attack are discharged within 4 hours. ${ }^{11-13}$ This short avoidable stay indicates that a significant number of preschool wheezers need not have sought clinical review at a secondary care setting. These differences will only be understood by studying the family perspective. A PROM could be used in the routine management of preschool children with recurrent wheeze, to direct discussions around important aspects of care. It could also be used as a marker of quality of care to assess performance in primary care and in different hospital trusts.

\section{ARE THERE SUITABLE PROMS IN CHILDREN WITH RECURRENT WHEEZE?}

For preschool children, disease control is assessed by the Test for Respiratory and Asthma control. ${ }^{14}$ The Paediatric Asthma Quality of life questionnaire is another tool used in younger children (more than 2 years old). There is also a version that is designed to be answered by parents. ${ }^{15} 16$ There are two other instruments attempting to assess the severity of preschool wheeze attacks and the main parental feelings during the episode. ${ }^{1718}$ Although these instruments demonstrate how families feel during acute attacks, they do not capture the changes in quality of their life over time and are not co-designed with families, unlike PROMs. Indeed, we recently published a spotlight which showed that there are no PROMs currently used for preschool children with wheeze in the UK, the USA, Argentina, Greece, Italy, Australia, Singapore and India. ${ }^{19}$ In summary, we have no PROMs for preschool wheeze, and, until such exist, we are unlikely to impact hospital attendances or assess new interventions in an appropriate manner.

\section{CONCLUSION}

Placing the individual at the centre of healthcare is the whole basis for modern medicine, and assessing whether this has been achieved throughout the whole cycle of care is very important. PROMs can be used to measure the success of treatment and quality of care in terms of which are important to patients. Further benefits include informing commissioning and use as endpoints in clinical trials. Clinicians should be assisted to use PROMs meaningfully as part of a management toolkit. In practice, this means they must be succinct. We do not have user-friendly PROMs for preschool wheeze. This omission needs to be rectified, and furthermore, suitable PROMs need to be developed for other paediatric diseases which currently lack them. Otherwise, the voices of parents and children will not be heard.

Contributors HM wrote the manuscript and $A B$ and $C G$ reviewed it.

Funding The authors have not declared a specific grant for this research from any funding agency in the public, commercial or not-for-profit sectors.

Competing interests None declared.

Provenance and peer review Commissioned; externally peer reviewed.

\section{ORCID iDs}

Heidi Makrinioti http://orcid.org/0000-0003-0832-2744

Andrew Bush http://orcid.org/0000-0001-6756-9822

\section{REFERENCES}

1 Baxter S, Clowes M, Muir D, et al. Supporting public involvement in interview and other panels: a systematic review. Health Expect 2017;20:807-17.

2 Porter ME. A strategy for health care reform-toward a valuebased system. N Engl J Med 2009;361:109-12.

3 Devlin NJ, Parkin D, Browne J. Patient-reported outcome measures in the NHS: new methods for analysing and reporting EQ-5D data. Health Econ 2010;19:886-905.

4 Haverman L, van Rossum MAJ, van Veenendaal M, et al. Effectiveness of a web-based application to monitor healthrelated quality of life. Pediatrics 2013;131:e533-43.

5 Appleby J, Poteliakhoff E, Shah K, et al. Using patient-reported outcome measures to estimate cost-effectiveness of hip replacements in English hospitals. J R Soc Med 2013;106:32331.

6 Weldring T, Smith SMS. Patient-reported outcomes (PROs) and patient-reported outcome measures (PROMs). Health Serv Insights 2013;6:61-8.

7 Reeve BB, Wyrwich KW, Wu AW, et al. ISOQOL recommends minimum standards for patient-reported outcome measures used in patient-centered outcomes and comparative effectiveness research. Qual Life Res 2013;22:1889-905.

8 Davies G, Paton JY, Beaton SJ, et al. Children admitted with acute wheeze/asthma during November 1998-2005: a national UK audit. Arch Dis Child 2008;93:952-8.

9 Bloom CI, Nissen F, Douglas IJ, et al. Exacerbation risk and characterisation of the UK's asthma population from infants to old age. Thorax 2018;73:313-20.

10 Brand PLP, Baraldi E, Bisgaard H, et al. Definition, assessment and treatment of wheezing disorders in preschool children: an evidence-based approach. Eur Respir J 2008;32:1096-110.

11 Foster SJ, Cooper MN, Oosterhof S, et al. Oral prednisolone in preschool children with virus-associated wheeze: a prospective, randomised, double-blind, placebo-controlled trial. Lancet Respir Med 2018;6:97-106.

12 Abaya R, Delgado EM, Scarfone RJ, et al. Improving efficiency of pediatric emergency asthma treatment by using metered dose inhaler. J Asthma 2018;258:1-8.

13 Staggs L, Peek M, Southard G, et al. Evaluating the length of stay and value of time in a pediatric emergency department with two models by comparing two different albuterol delivery systems. J Med Econ 2012;15:704-11.

14 Zeiger RS, Mellon M, Chipps B, et al. Test for respiratory and asthma control in kids (track): clinically meaningful changes in score. J Allergy Clin Immunol 2011;128:983-8.

15 Seid M, Limbers CA, Driscoll KA, et al. Reliability, validity, and responsiveness of the pediatric quality of life inventory (PedsQL) generic core scales and asthma symptoms scale in vulnerable children with asthma. J Asthma 2010;47:170-7. 
16 Varni JW, Burwinkle TM, Rapoff MA, et al. The PedsQL in pediatric asthma: reliability and validity of the pediatric quality of life inventory generic core scales and asthma module. J Behav Med 2004;27:297-318.

17 Ducharme FM, Jensen ME, Mendelson MJ, et al. Asthma flare-up diary for young children to monitor the severity of exacerbations. J Allergy Clin Immunol 2016;137:744-9.

18 Jensen ME, Mendelson MJ, Desplats E, et al. Caregiver's functional status during a young child's asthma exacerbation: a validated instrument. J Allergy Clin Immunol 2016;137:782-8.
19 Makrinioti H, Klaber R, Watson M. Around the world: preschool wheeze. Lancet Respir Med 2017;5:688-9.

20 Halleran DR, Lane VA, Leonhart KL, et al. Development of a patient-reported experience and outcome measures in pediatric patients undergoing bowel management for constipation and fecal incontinence. J Pediatr Gastroenterol Nutr 2019;69:1-8.

21 Wegmann H, Janout S, Novak M, et al. Surgical treatment of posterior cruciate ligament lesions does not cause growth disturbances in pediatric patients. Knee Surg Sports Traumatol Arthrosc 2019;27:2704-9. 